\title{
Toward Performance-based Evaluation for Offshore Wind Turbine Jacket Support Structures
}

\author{
K. Wei ${ }^{1, *}$, S. R. Arwade ${ }^{1}$, A. T. Myers ${ }^{2}$, S. Hallowell ${ }^{2}$, \\ J. F. Hajjar ${ }^{2}$, E. M. Hines ${ }^{3,4}$, W. Pang ${ }^{5}$ \\ ${ }^{1}$ Department of Civil and Environmental Engineering, University of Massachusetts Amherst, 130 Natural \\ Resources Road, Amherst, MA 01003; \\ ${ }^{2}$ Department of Civil and Environmental Engineering, Northeastern University, 360 Huntington Avenue, Boston, \\ MA 02115; \\ ${ }^{3}$ Department of Civil and Environmental Engineering, Tufts University, 419 Boston Avenue, Medford, MA \\ 02155 ; \\ ${ }^{4}$ LeMessurier Consultants, Inc., 1380 Soldiers Field Road, Boston, MA 02135; \\ ${ }^{5}$ Glenn Department of Civil Engineering, Clemson University, Lowry Hall, Clemson, SC 29634
}

\begin{abstract}
This paper introduces a framework for the assessment of damage of offshore wind turbines (OWTs) supported by jackets under extreme environmental loadings. Performance levels/damage states, ranging from operational/undamaged to near collapse/severely damaged, are defined based on static pushover analyses. An example performance assessment is presented for an OWT supported by a jacket based on environmental conditions for a site off Massachusetts along U.S. Atlantic coast. The environmental conditions are characterized based on two methods for estimating wind and wave conditions, one on extrapolation of NOAA buoy measurements and one on a stochastic hurricane catalog, and two models for extreme wave height, one on the crest height and one on the zero-up-crossing height. Using probabilistic models for demands and capacities, two curves of fragility, one estimating the initiation of yielding and the other estimating the onset of collapse, are developed to distinguish between the three damage states. The curves are applied to four combinations of two environmental hazard models and two extreme wave height models, and significant differences are found in the probability of damage among the four combinations of models. The findings have potential implications for the evaluation of the overall risk profile and associated performance for offshore wind farms.
\end{abstract}

\section{KEYWORDS:}

Offshore wind turbines; jacket; performance; extreme metocean conditions; fragility; probabilistic models

\footnotetext{
${ }^{*}$ Corresponding author. $\mathrm{PhD}$, Post-doctoral research associate.

Address: 42D Marston Hall, University of Massachusetts Amherst, 130 Natural Resources Road, Amherst, MA 01003.

Telephone: (+1) 413-577-1242.

Email: kaiwei.tj@gmail.com
} 


\section{INTRODUCTION}

Development of the offshore wind energy resource is being pursued along the Atlantic coast of the U.S. because of the abundant wind resource, extensive available space for wind farm installation and proximity to major population centers [1]. Successful exploitation of offshore wind energy depends upon the reliability of the structures that support the rotor and nacelle of the turbine. Current design practice requires an elastic response for conditions with mean return periods (MRPs) of 50 to 100 years, with prescribed load and material factors intended to ensure target reliability levels [2]. The appropriate target reliability level for a given structure is set in accordance with its safety class and the severity of the consequences associated with structural failure [2]. The Atlantic coast, however, provides designers of support structures of offshore wind turbines (OWTs) with additional challenges absent from the European design experience and related to the presence of hurricane risk off the Atlantic coast [3]. Given these potentially extreme conditions, a more detailed examination of postelastic structural performance during events occurring at greater return periods than the design conditions is required for a full understanding of the risk posed to OWTs by extreme events. This paper presents a framework for performance assessment of OWT support structures under extreme wind and wave events. A performance assessment is provided for an illustrative OWT supported by a jacket based on two performance levels that delimit between three damage states of the support structure. The results of the assessment are probabilities of damage indexed to the MRP of the environmental conditions, illustrating the relationship between structural demand and the probability of the structure being classified as being in a particular damage state that is linked to a particular performance level. These results, which extend to MRPs well beyond those considered in design, hold the promise of bridging the gap between the risk of wind farm damage and the interests of engineers, developers, regulators, decision makers, and other stakeholders.

Fragility analyses are commonly used in earthquake engineering as an essential tool for assessing the vulnerability of structures and offer a means of communicating the probability of damage over a range of potential loading intensities [4-6]. There have been some efforts to assess fragility of onshore and offshore wind turbines. Nuta et al. [7] presented a method for determining the probability of damage for onshore wind turbine towers at various levels of damage and numerically investigated the seismic behavior of the tubular steel tower of a typical 1.65 MW parked wind turbine. Myers et al. [8] assessed the fragility with respect to yielding of an $80 \mathrm{~m}$ tall onshore wind turbine tower as a function of ground motion intensity and frequency content. Kim et al. [9] studied the seismic fragility of a 5MW OWT monopile including nonlinear soil-structure interaction. Ciampoli and Petrini [10], inspired by seismic fragility analysis, studied various sources of loading uncertainty of OWTs in the framework of performance-based engineering. Quilligan et al. [11] selected hub-height wind speed as the intensity measure and investigated the fragility of onshore wind towers as a function of materials, hub height and wind speeds. Mardfekri and Gardoni [12] developed probabilistic models for the deformation, shear and moment demands on an OWT monopile subject to operational wind, wave and current loadings and assessed the fragility of OWT monopiles under these loadings as a function of wind speed or wave height. Cheng et al. [13] studied the extreme response distribution of OWTs under operational wind and wave using a reliabilitybased approach, which can be extended to evaluate structural fragility. Fallon [14] developed a probabilistic demand model to assess the fragility of an asymmetric offshore oil jacket platform considering serviceability and ultimate performance levels. Taflanidis et al. [15] focused on the probabilistic characterization of the uncertainty of loads, structure and performance and presented a generalized framework for risk assessment of OWTs under extreme wind and wave conditions without discussing the fragility estimation specifically. 
The fragility of OWTs supported by jackets-proposed for use in deeper water than monopiles - under the combination of extreme wind and wave conditions has received less attention and yet remains important and challenging since proposed offshore installations are moving to deeper water. Furthermore, jackets have a greater degree of indeterminacy than monopiles, and therefore have the potential for richer post-elastic performance. An x-braced jacket is, essentially, a three-dimensional frame for which alternate load paths exist should a given member or subset of members lose partial or complete load-carrying capacity. Because of this redundancy a jacket structure can be expected to exhibit some degree of ductility and a post-peak response that does not consist solely of a steep drop in load-carrying capacity. A monopile, on the other hand, consists of a single cantilevered beam-column projecting from the mudline with no viable alternate load paths should the monopile itself lose load-carrying capacity.

This paper focuses on the performance of OWTs supported by jackets. A framework for calculating probability of damage as a function of the MRP of wind and wave conditions is proposed. In the framework, three damage states, undamaged, damaged and severely damaged, corresponding to three performance levels, operational, non-operational and near collapse, are defined. As a first step in the development of a Performance Based Engineering (PBE) framework for OWT support structures, the performance is evaluated for an example jacket structure using a static pushover approach. A simplified analysis method is implemented here for efficiency and to enable initial examination of the interplay between complicated offshore loading conditions and structural performance. Development of the PBE framework beyond the preliminary version described here into one that could be used in design and assessment will require incorporation of more advanced analysis techniques to predict performance. For example, fracture, fatigue, corrosion, and buckling/instability should all be included in a complete PBE framework for offshore jackets. In this paper, two fragility functions are proposed to delineate between these three damage states and performance levels: the first fragility function estimates the probability that yielding has initiated somewhere in the jacket structure and the second estimates the probability that a plastic mechanism has developed in the jacket. Probabilistic models for the wind and wave conditions are developed and response surfaces, based on Incremental Wind-Wave Analysis [16] and functions of wind speed and wave height, are used to define the demands and capacities of each performance level, including uncertainty in structural material properties. Monte Carlo simulation using these response surfaces is finally used to assess performance across a range of MRPs.

\section{OVERVIEW OF METHOD}

\subsection{General configurations and assumptions}

Several simplifying assumptions regarding the structural configuration and loading conditions are made to allow primary attention to be paid to the development of the performance assessment framework for OWTs supported by jackets. First, the jacket is assumed to have four legs and be square in plan (Figure 1); second, the wind and wave loads are assumed to be co-directional and approaching the jacket broadside; third, environmental conditions - wind speed and wave height - are considered independently and parameterized by a single MRP; fourth, static nonlinear pushover analysis is used to assess the damage state of the jacket using a stress-resultant plasticity formulation with plastic hinges simulating moment and axial force interaction and assuming elastic perfectly plastic material behavior. 


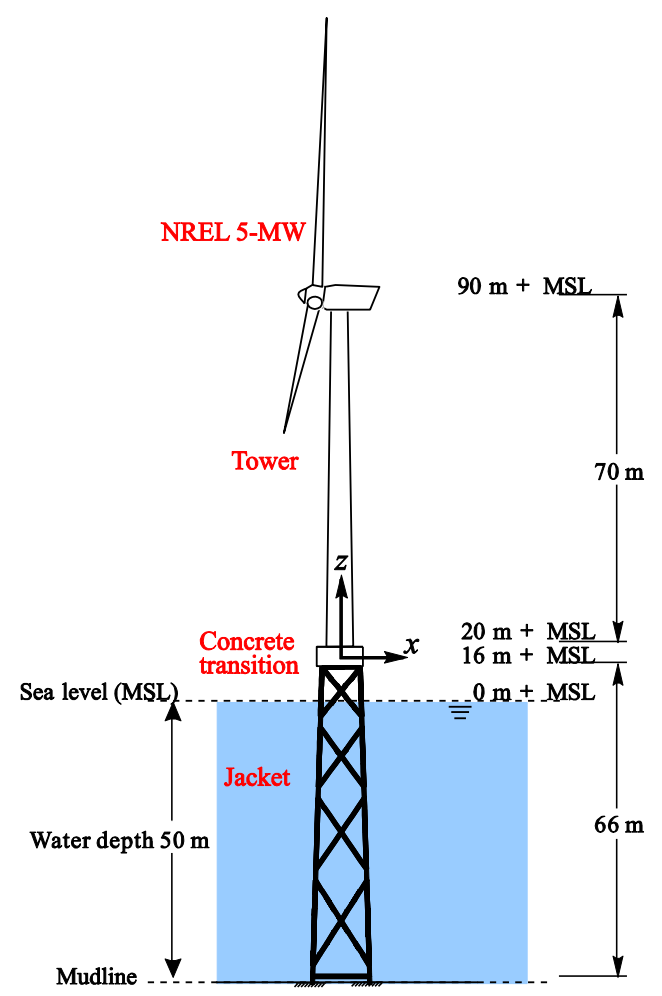

(a)

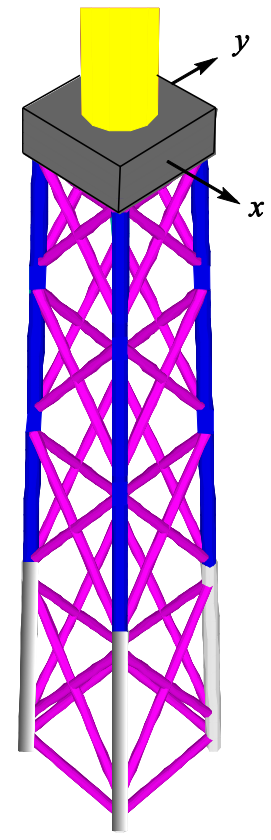

(b)

Figure 1 Schematics of the OWT supported by a jacket: (a) dimensions of reference jacket support structure; (b) 3D view of jacket components (colors indicate groups of members with identical cross sections). See reference [16] for details.

\subsection{Performance assessment method}

Fragility is the conditional probability of a structural damage measure (DM) attaining or exceeding a damage state given an intensity measure (IM) that characterizes the environmental conditions. The conditional probability of the $i^{\text {th }}$ damage state $P_{f, i \mid I M}$ can be evaluated by [17]:

$$
P_{f, i \mid M}=P\left[D M_{i} \mid E D P=e d p\right] P[E D P=e d p \mid I M=i m]
$$

where IM represents the intensity measure of the environmental action, $D M_{i}$ is the damage measure corresponding to the $i^{\text {th }}$ damage state and EDP is the engineering demand parameter. Lower case versions of these symbols represent values of the, generally random, variables IM and EDP. $P\left[D M_{i} \mid E D P=e d p\right]$ is the probability that the structure reaches damage state $i$ given the EDP value. The EDP value in turn comes from the IM, probabilistically, as $P[E D P=e d p \mid I M=i m]$. The probability of the $i^{t h}$ damage state is then obtained by calculating $P_{f, i}$ for a range of intensity measures with associated probability of occurrence.

In this study, static pushover analysis is used to map the IM directly onto the damage state, thereby obviating the need to explicitly define and model a probabilistic EDP that can be conditioned on the IM. This simplification is introduced here to facilitate development of the performance evaluation framework for offshore wind turbine support structures and it is expected that further development of the framework will entail enhanced modeling and analysis approaches that would result in EDP being treated probabilistically. This is in contrast, for example, to the case in seismic analysis where the IM may be the spectral acceleration (SA), which leads to a range of interstory drift ratios (a typical choice for EDP in 
the seismic case) because SA is only a reduced order description of the ground motion and because of structural uncertainty. Although Eq. (1) could in principle be rewritten as

$$
P_{f, i \mid M}=P\left[D M_{i} \mid I M=i m\right]
$$

here, eliminating the EDP from the formulation, base shear is retained as a formal representation of the EDP both to remain consistent with a formulation used in earthquake engineering and to allow for the possibility of further development of the framework in such a way that EDP would become a probabilistic function of IM. Since static pushover analyses are used here, dynamic effects are neglected, allowing an initial investigation of damage and performance of offshore wind jacket structures in a computationally efficient manner.

The fragility function can be expressed in terms of structural capacities and demand as $P\left[D M_{i} \mid E D P=e d p\right]=P\left(C_{i} \leq D \mid E D P=e d p\right)$, where $C_{i}$ is the capacity corresponding to the $i^{\text {th }}$ damage state and D is the static elastic demand corresponding to the IM. Here, the MRP is used as a surrogate for the IM (and hereafter will be referred to as the IM itself). Although MRP is a time-dimensioned value that represents the frequency of occurrence of an environmental condition, by using MRP as a surrogate for the pair of IMs (wind speed and wave height) that affect OWT platforms, the performance evaluation framework can be cast in such a way that the IM (in this case its surrogate, MRP) is a scalar. To introduce the wind speed and wave height directly as IMs would require treatment of a vector-valued IM, a significant complication that, at this point in the development of the performance evaluation framework for OWT platforms, does not add significant value. Since the MRP is uniquely coupled to the wave height and the hub height hourly mean wind speed [16], the method is equivalent to one in which wind speed and wave height are treated as IMs.

In this paper two methods are considered for estimating wind and wave conditions at various MRPs, one based on decades of continuous measurements of the sea state and wind speeds provided by the National Data Buoy Center of the US National Oceanic and Atmospheric Administration (NOAA) [18] and the second based on a synthetic stochastic catalog of hurricanes [19]. The first is referred to herein as the NOAA-based environmental conditions and the second as the hurricane-based environmental conditions.

For the NOAA model, hub height mean wind speed $V_{w}(\mathrm{MRP})$ and significant wave height $H_{\mathrm{s}}(\mathrm{MRP})$ are obtained by fitting a generalized extreme value (GEV) distribution to the annual maxima of measured wind speed and wave height [20] and then extracting tail values of the $\mathrm{CDF}$ corresponding to the target MRP. This approach is generally viewed as conservative since it models annual maxima of wind speed and wave height independently and then combines them as if they had occurred simultaneously. Due to relatively short record lengths (20-30 years at most), however, the NOAA model is unlikely to capture enough extreme events to return wind speeds and wave heights that are reflective of hurricane conditions. Since models for the wind speed and wave height are developed independent of one another it is possible to use a single MRP to define both a wind speed and wave height. In this way, an MRP is selected and then each GEV distribution is inverted to calculate the corresponding wind speed or wave height. The resulting wind speed and wave height are then combined and assumed to reflect the extreme wind and wave conditions corresponding to the given MRP. One could, instead, rely on a joint distribution of wind speed and wave height to characterize the hazard, as is done in [21], but doing so is challenging due to the relative paucity of data available for calibrating joint models and because it makes it challenging to define a scalar intensity measure.

For the hurricane model, the stochastic catalog provides a set of hurricanes designed to be representative of 100,000 years of hurricane activity in the Atlantic Basin. Combining this 
catalog with physical models such as the Holland and Young models to estimate the wind speed and wave height $[22,23]$ of each storm at a given site, the mean wind speed and significant wave height corresponding to a given MRP can be computed.

Fragility and performance, however, is better predicted with extreme values of the wave height and wind speed rather than more central values such as the significant wave height and mean wind speed. As such, one approach is to generate samples of an irregular wave train and then perform a static pushover analysis for the extreme wave of each wave train. This procedure is computationally inefficient, however, since generation of the irregular wave trains requires computation time and only the extreme wave is used in analysis. Therefore, it is advantageous to develop a probabilistic model for the maximum wave height occurring in an irregular wave train and then, by sampling from that model, obtain isolated waves for use in the pushover analysis. This procedure then uses existing models to subsequently compute the internal kinematics of the isolated wave [24].

For an irregular wave train, however, the definition of the extreme wave is ambiguous, and here two definitions are investigated. The first treats the extreme wave height as $H_{e, \text { crest }}$, the crest-to-trough height of an isolated wave with crest height equal to the maximum crest height $C_{e}$ extracted from the irregular wave train. The second considers the extreme wave height as $H_{e, \text { cross }}$, the crest-to-trough height of the wave with the maximum crest-to-trough height in the irregular wave train. The wave extracted by the second method is usually called the maximum zero-up-crossing wave and that term is used for the remainder of this paper [24]. The purpose of implementing both extreme wave height models here is to demonstrate the sensitivity of the fragility to the extreme wave height model.

For both extreme wave height models a distortion of the wave form occurs when an isolated wave is generated to match either $C_{e}$ or $H_{e, \text { cross }}$ using nonlinear stream function theory [25]. In the case of matching $C_{e}$, the crest-to-trough height of the isolated wave will differ from the upcrossing height of the wave with maximum crest height and in the case of matching $H_{e, \text { cross }}$, the crest height of the isolated wave will differ from the crest height of the maximum zeroup-crossing wave. In the following sections, it will be shown that the crest height of an isolated wave generated to match $H_{e, \text { cross }}$ is typically larger than that which occurs in the irregular wave train, leading to higher estimates of probability of damage. Stream function theory was selected as a wave model in order to be able to match the geometry and kinematics of the large waves that cause damage to offshore structures [26]. Tenth order solutions have been used as the default, although for waves larger than $28 \mathrm{~m}$, 17th order solutions were required [27]. Other options for wave modeling include Airy and Stokes theories, but Airy provides only linear sinusoidal wave geometry and Stokes theory contains lower order nonlinearity than the stream function models used here. Stream function calculations, though of high order, are computationally inexpensive for isolated waves and therefore do not compromise the overall efficiency of the method introduced here.

Calculation of extreme wind loads is substantially more straightforward than that for waves, and the 3 second wind gust at hub height extracted from a turbulent wind time history is treated as the extreme wind speed.

Probabilistic models for these extreme wave heights and wind speeds as functions of $H_{s}$ and $V_{w}$ are developed and used to sample random values of the extreme wind speed and wave height for use in the pushover analysis. The following procedure is then used to complete the fragility analysis:

1. Select a series $\mathrm{MRP}_{j} ; \mathrm{j}=1, \ldots, n_{M R P}$ as the hazard IMs of interest. 
2. For each $\mathrm{MRP}_{j}$, the extreme wind speed $\left(V_{e}\right)$, the extreme wave height $\left(H_{e, \text { crest }}\right.$ or $\left.H_{e, \text { cross }}\right)$ and the material yield stress $\left(F_{y}\right)$ are treated as independent random variables, and $n_{s}$ samples are generated by Monte Carlo simulation. Details on distributions and probability models used in the example are provided later.

3. For each sample, the demand base shear $D$ and the base shear capacities $C_{1}$ and $C_{2}$ corresponding to each fragility function are computed with modifications to account for uncertainty in the material yield stress.

4. For each sample, the demand base shear is compared to the damage state capacities to evaluate the damage state for that sample.

5. The probability of a given damage state $i$ at a given intensity measure is estimated as the number of samples that attain a given damage state $n_{s, i}$ divided by the total number of samples $n_{s}$.

\section{EXAMPLE PERFORMANCE EVALUTION}

\subsection{Site description, environmental and structural model}

This paper illustrates the computation of probabilities of damage using the NREL offshore 5MW baseline wind turbine [28] supported by a jacket, installed in $50 \mathrm{~m}$ water depth and subject to extreme environmental loadings. The jacket design is taken from the UPWIND project of the European Union [29]. The original jacket is designed for 50-year extreme environmental conditions appropriate for a location in the North Sea (i.e., a 10-min mean hub height wind speed of $42.7 \mathrm{~m} / \mathrm{s}$ and a significant wave height of $9.4 \mathrm{~m}$ in a water depth of 50 $\mathrm{m})$.

As shown in Figure 1, the rotor-nacelle-assembly (RNA) of the considered turbine has a total mass of $350,000 \mathrm{~kg}$ and the jacket consists of four legs with four levels of X-braces and cross braces. A concrete deck with a mass of $666,000 \mathrm{~kg}$ and plan dimensions of $4.0 \times 9.6 \times 9.6 \mathrm{~m}$ is positioned on top of the jacket and serves as a support platform for the tower of the turbine. The jacket legs are assumed to be fully fixed at the mudline in the absence of information regarding pile-leg detailing and geotechnical conditions. The geometrical properties of the braces and legs of the model are listed in Table 1.

Table 1 Geometrical properties of structural members in the UPWIND jacket.

\begin{tabular}{c|c|c|c}
\hline Component & Color in Figure 1 & Diameter (m) & Thickness (m) \\
\hline Legs at lowest level & Gray & 1.20 & 0.05 \\
\hline Legs at 2nd to 4th level & Blue & 1.20 & 0.04 \\
\hline Braces & Purple & 0.80 & 0.02 \\
\hline
\end{tabular}

Material nonlinearity is considered through interacting three-dimensional axial force-bending moment stress-resultant plasticity models that are assigned at finite-length plastic hinges at the ends of the jacket members to simulate post-yield behavior in the pushover analyses. The moment-rotation behavior is assumed to be trilinear with stiffness changes occurring at the yield and plastic moments, and perfectly plastic behavior assumed after the plastic moment is reached. The steel is assumed to have a yield stress of $380 \mathrm{MPa}$ and a hinge rotation at the fully plastic moment equal to $\mathrm{f}_{\mathrm{y}} \mathrm{ZL} /(6 \mathrm{EI})$, where $\mathrm{Z}$ is the plastic modulus of the section, $\mathrm{L}$ is the hinge length, $\mathrm{E}$ is the young's modulus and $\mathrm{I}$ is the moment of inertia of the section. 
Hinge length is modeled as 0.05 times the element length [30] and each structural member is discretized into 8 Euler-Bernoulli beam elements.

The site selected for study is off the coast of the state of Massachusetts, where NOAA data buoy 44008 is located $\left(40.502^{\circ} \mathrm{N} 69.247^{\circ} \mathrm{W}\right)$ and has recorded hourly measurements of wind and wave for 31 years. It should be noted that the record is not complete and in fact data are lacking for many extreme events. Although water depth at the site is $65.8 \mathrm{~m}$, the structural and wave models used here use a $50 \mathrm{~m}$ water depth to conform to the water depth for which the jacket structure was designed. Two approaches to estimate the environmental conditions are used here: (1) Generalized Extreme Value distributions (GEV) are fit to 31 values of annual maxima of significant wave height and hourly wind speed at $5 \mathrm{~m}$ elevation. This data is directly available from the NOAA data buoy, and a correction factor of 1.472 is applied to adjust the $5 \mathrm{~m}$ hourly wind speed to a 10-min wind speed at hub height $(90 \mathrm{~m})$ [31]. Independent probabilistic models for wind and wave conditions are used to generate wind speed and wave height corresponding to a given MRP. As described above, the MRP is a surrogate for the joint wind-wave IM in this example. (2) A stochastic catalog of simulated hurricanes [19], representative of 100,000 years of hurricane activity at the site, coupled with parametric models for predicting wind speed (Holland's model [22]) and significant wave height (Young's model [23]) given hurricane parameters, allows fitting of GEV distributions to the hurricane generated wind speeds and wave heights. The Holland model gives a steady gradient wind speed that is converted from gradient to $10 \mathrm{~m}$ using a constant ratio of 0.71 [32]. This is then converted to 10-min wind speed at hub height $(90 \mathrm{~m})$ using a factor of 1.289 [31]. For both cases (1) and (2), the value of the wind speed and wave height corresponding to a specified MRP can be extracted from the upper tail of the GEV distribution representing continuous measured data and synthetic hurricane data. It is important to note that, in case of the NOAA data, the upper tail of the distribution represents extrapolation from the available data to a greater extent than is commonly accepted in practice, particularly in the presence of hurricanes.

Figure 2 shows the significant wave height $H_{s}$ and 10-min hub height wind speed $V_{w}$ corresponding to the NOAA and hurricane datasets for the Massachusetts site at selected MRPs. The wind and wave conditions corresponding to a given MRP differ dramatically between the two hazard models. To illustrate this difference quantitatively, consider a hypothetical structure that fails at a significant wave height of $16 \mathrm{~m}$, corresponding to an MRP of 100,000 years for the NOAA model and 250 years for the hurricane model. These MRPs correspond to annual failure probabilities of $1 \times 10^{-5}$ and $4 \times 10^{-3}$, meaning that choice of environmental model can result in a difference in annual failure probability of two full orders of magnitude. The difference between the hurricane and NOAA data grow greatly at longer MRPs, while, at design MRPs, such as 50 years, the difference in wave height is only $11.5 \mathrm{~m}$ to $12.1 \mathrm{~m}$, whereas at an MRP of 250 years, the difference is approximately $13 \mathrm{~m}$ to $16 \mathrm{~m}$. Therefore, the hurricane-based environmental model has much greater effect at long MRPs and is therefore particularly critical for assessing the risk posed to OWT support structures by rare events that are outside the consideration of typical design approaches. This result indicates the importance of calibrating a probabilistic model with appropriate and sufficient data. The NOAA model is included here, although the dataset is insufficient for representation of extreme event hazard, for comparison to the hurricane catalog data to illustrate clearly the potential dangers of using easy-to-obtain data (the NOAA data) for a purpose for which it was not intended (extreme event modeling). The hurricane based wind speeds are largely consistent with those used in the onshore civil design community. For example, for a coastal site near the data buoy site the current ASCE 7-10 load determination 
specification gives a 100 year wind speed of $43 \mathrm{~m} / \mathrm{s}$ which compares well with the predicted offshore speed of $47 \mathrm{~m} / \mathrm{s}$ calculated here.

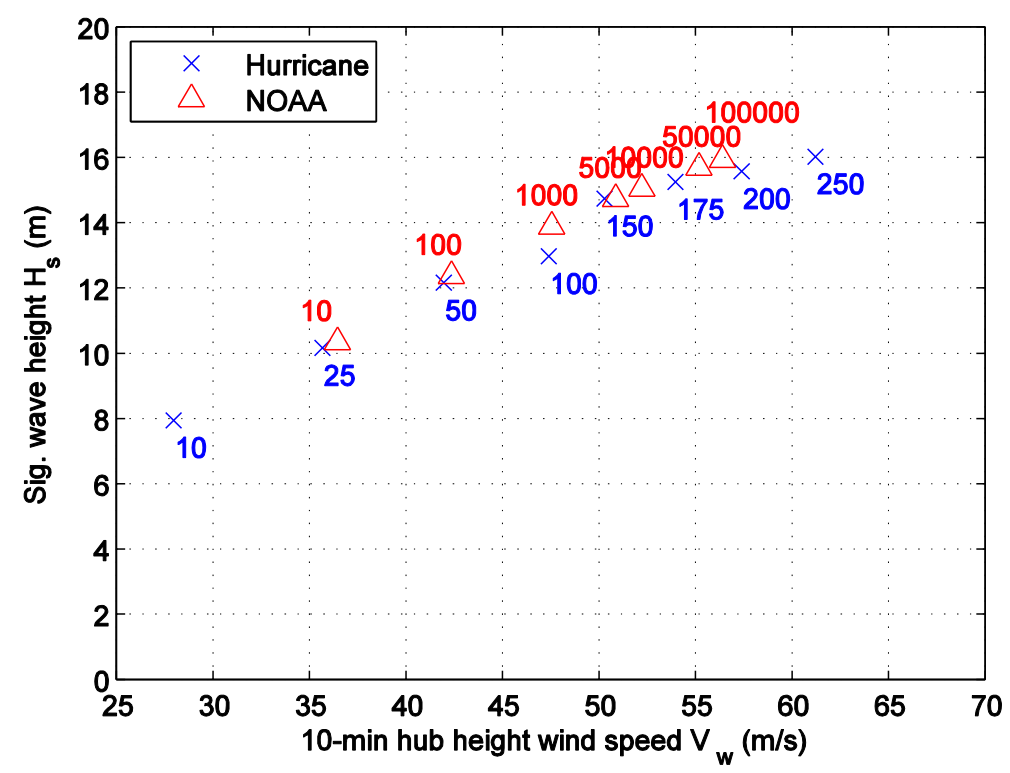

Figure 2 Significant wave height and 10-min hub height wind speed for Massachusetts site at various MRPs, assuming wind and wave are independently distributed. Triangle markers give the values of the wind and wave conditions from NOAA measured annual maxima at $M R P=[10,100,1000,5000,10000,50000,100000]$ years and $X$ markers give the values of the wind and wave conditions from synthetic hurricane catalogue at MRP $=[10,25,50,100,150,175,200,250]$ years.

\subsection{Probabilistic extreme wave height model}

In a static pushover analysis, an extreme wave is used to represent the maximum loading that will occur at a given MRP. Since the NOAA and hurricane data lead to values of $H_{s}$ at each MRP, a probabilistic mapping from $H_{s}$ to the $H_{e, c r e s t}$ and $H_{e, c r o s s}$ is needed to inform the fragility analysis. To generate such a model, 1000 samples of a one-hour irregular wave train are generated for a range of values of $H_{s}$. These irregular wave trains are generated using nonlinear-irregular wave modeling [33] and a JONSWAP spectrum [34] with a peak spectral wave period $T_{p}$ considered deterministically as,

$$
T_{p}=11.1 \sqrt{H_{s} / g}
$$

which corresponds to the lower bound of wave period $T_{z}$ recommended by the IEC [2]. The lower bound period is used here to be consistent with specification language and industry practice although the peak spectral period is known to have site-specific characteristics [35]. This modeling choice thus removes one parameter from the environmental model and results in a conservative estimate of loading since waves with lower periods result in higher structural loads. Eq. (3) can also be used to estimate wave period $T_{z}$ of the isolated extreme wave by replacing $T_{p}$ with $T_{z}$ and adjusting the wave height according to $H_{s}=H_{e} / 1.86$. This results in wave kinematics being a function of wave height only. Although using Eq. (3) for wave period significantly simplifies the treatment, period should be included as an uncertain component of the hazard model and calibrated to available data as development of performance evaluation frameworks continues [21]. 


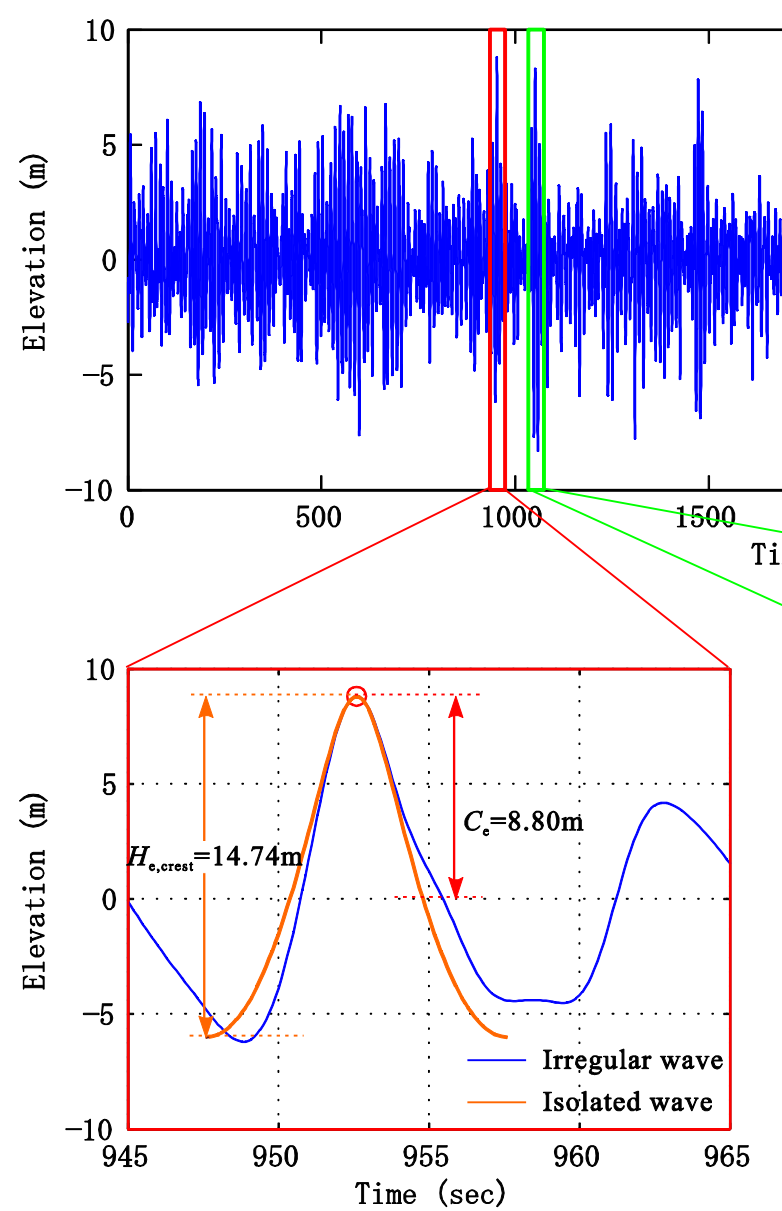

(b)

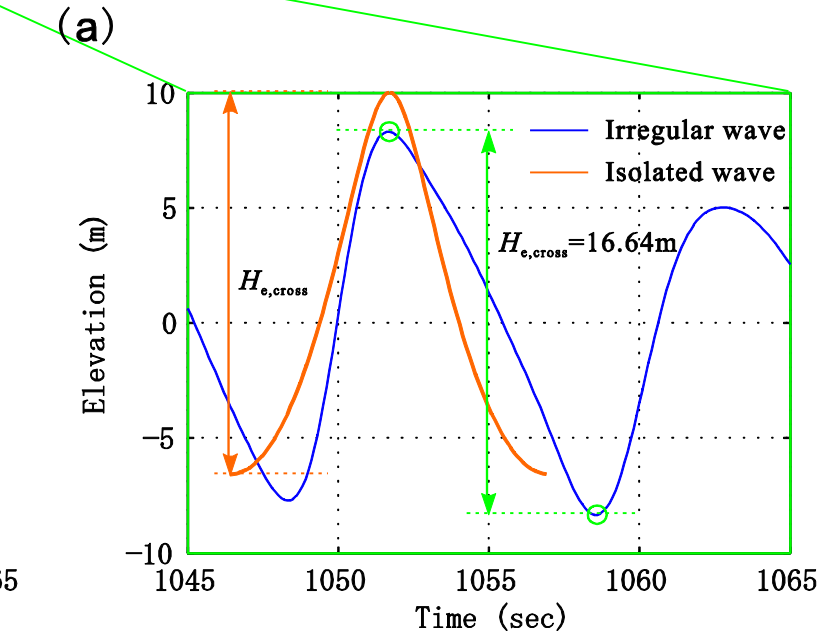

(c)

Figure 3 Difference between crest and zero-up-crossing wave height $\left(C_{\mathrm{e}}-\right.$ maximum wave crest height; $\boldsymbol{H}_{\mathrm{e}, \mathrm{cross}}$ - maximum zero-up-crossing wave height ): (a) illustration of an irregular wave train; (b) detail of maximum wave crest height and the isolated wave of $\boldsymbol{H}_{\mathrm{e}, \text { crest }}$ modeled by stream function; (c) detail of maximum zero-up-crossing wave height and the isolated wave of $H_{\mathrm{e}, \text { cross }}$ modeled by stream function.

As introduced earlier, two versions of the extreme wave height are considered here, one corresponding to the wave with the maximum crest height $H_{e, \text { crest }}$ and one to the wave with the maximum zero-up-crossing wave height $H_{e, \text { cross }}$. In each case, the extreme wave is extracted from simulated irregular wave trains, but, in the first case, the extreme wave is defined as that with the maximum crest height and, in the second, as the wave with the maximum crest to following trough height. Figure 3 a shows, for one sample of an irregular wave train with $H_{s}=10 \mathrm{~m}$, the extreme wave as defined by each of the two criteria described above. Typically, the wave with maximum crest height (Figure 3b) and the wave with maximum zero-up-crossing height (Figure 3c) are not the same wave, and such is the case in this example. Nonlinear stream function theory [25] is used in the example to compute water particle velocities and accelerations along the water depth.

Since stream function theory takes the zero-up-crossing height as a direct input, $H_{e, \text { cross }}$ can be used directly as an input to the stream function. When the goal is to match, $C_{e}$, however, the zero-up-crossing height, $H_{e, \text { crest }}$, corresponding to the target crest height must be calculated. The relationship between $C_{e}$ and $H_{e, \text { crest }}$ from stream function of tenth or higher order is, for 50 m water depth, 


$$
H_{e, \text { crest }}=0.022 C_{e}^{2}+1.87 C_{e}
$$

where both units of wave height $H_{e, c r e s t}$ and crest height $C_{e}$ are in meters. Note that for large waves $H_{e, \text { crest }}<2 C_{e}$ (see Fig. 4).

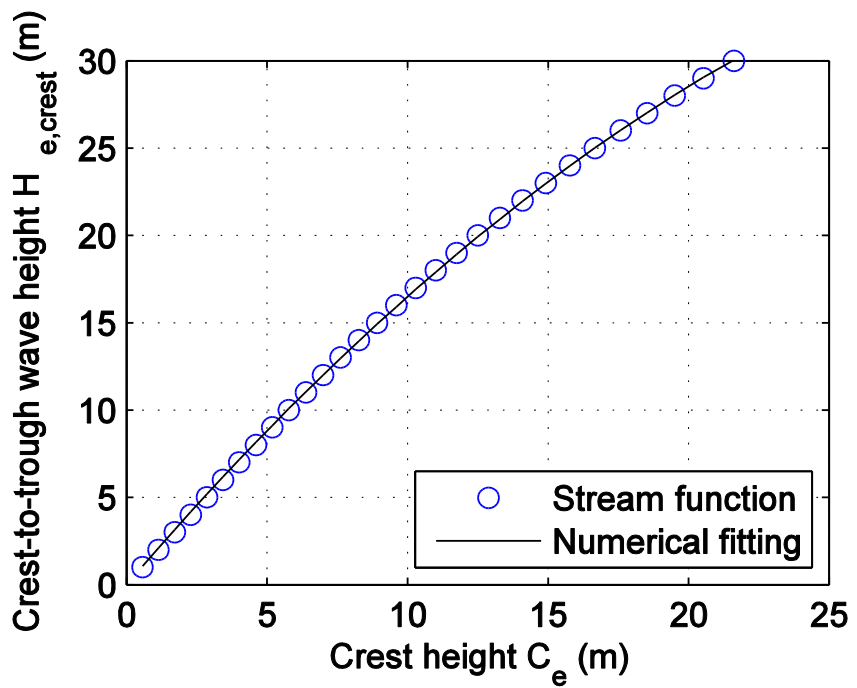

Figure 4 Polynomial fitting of wave height as a function of crest from stream function.

In the example shown in Figure 3, the maximum crest height $C_{e}$ equals $8.80 \mathrm{~m}$ and the maximum zero-up-crossing wave height $H_{e, \text { cross }}$ equals $16.64 \mathrm{~m}$. The wave height $H_{e, \text { crest }}$ associated with maximum crest height $C_{e}$ is $14.74 \mathrm{~m}$ according to Eq. (4). The isolated wave elevation profiles of $H_{e, \text { crest }}$ and $H_{e, \text { cross }}$ based on stream function are also plotted in Figure 3(b) and (c), separately. Although in the irregular wave train, the maximum crest height $C_{e}$ is higher than the crest height that accompanies the maximum zero up-crossing wave height, the isolated wave generated using stream function theory with a target zero-up-crossing wave height has an associated crest height that exceeds $C_{e}$ by $1.20 \mathrm{~m}$ due to nonlinearity in the stream function theory.

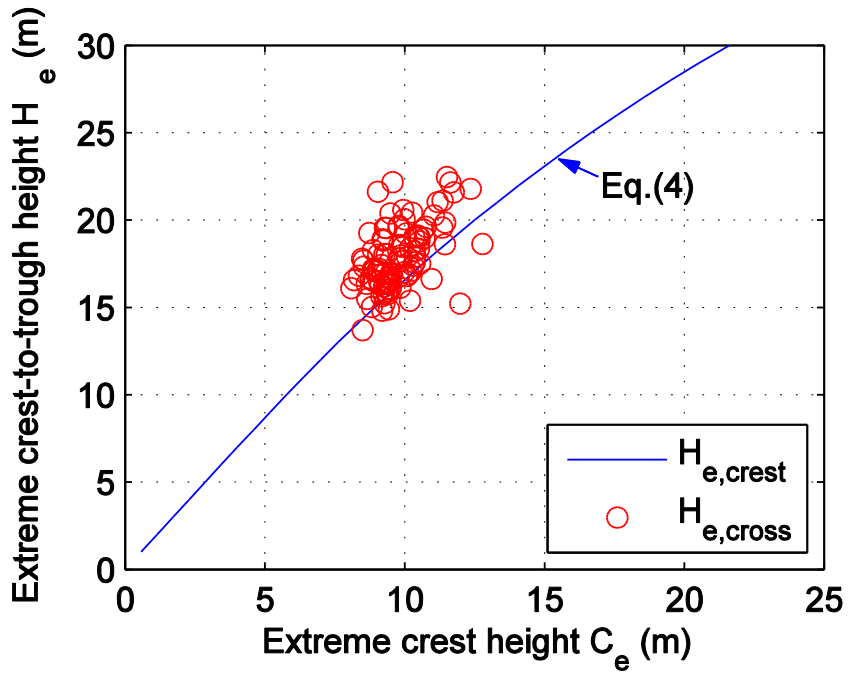

Figure 5 Scatter of $C_{e}$ and $H_{e, c r o s s}$ of 100 different one hour irregular wave train examples with $H_{s}=10 \mathrm{~m}$ and $H_{e, \text { crest }}$ curve as a function of $C_{e}$ (Eq. (4)).

Figure 5 compares the maximum zero-up-crossing wave height $H_{e, \text { cross }}$ and $H_{e, \text { crest }}$ of an isolated wave with crest equal to maximum crest height $C_{e}$. The figure shows 100 irregular 
wave train examples with $H_{s}=10 \mathrm{~m}$. Taking $C_{e}=10 \mathrm{~m}$ as an example, $H_{e, \text { cross }}$ (the red dots in the figure) in the irregular wave train is usually larger than $H_{e, c r e s t}$ (as defined by the blue solid line) of an isolated wave with crest height equal to $C_{e}$ of the irregular wave ( $91 \%$ of the samples have $H_{e, \text { cross }}$ larger than $H_{e, \text { crest }}$ ). Both Figure 3 and 5 show that the extreme wave model based on zero-up-crossing will tend to generate isolated waves with larger crest heights even though the crest height in the irregular wave train may be lower. Considering the extreme zero-up-crossing wave as characteristic of the extreme wave hazard has been commonly assumed in practice [36] but may result in overestimates of failure probability. This finding is based on stream function calculations and would benefit from further numerical and experimental investigations of the geometry and kinematics of the complex irregular wave trains that occur in the offshore environment.

Since the primary objective of this paper is to establish a framework for performance based design and assessment of OWTs supported by jacket structures, each of the wave height models proposed above (crest height or zero-up-crossing height) are carried through the remainder of the paper and comparisons between the results obtained using the two models are made.

A three-parameter generalized extreme value (GEV) distribution [37] is used to model the extreme crest heights $C_{e}$ and zero-crossing wave heights $H_{e, \text { cross }}$. For the use of individual wave modeling, the crest height $C_{e}$ should be transformed into $H_{e, \text { crest }}$ according to Eq.(4). The GEV distribution has probability density function,

$$
f(x)=\frac{1}{\sigma}\left[1+\xi\left(\frac{x-\mu}{\sigma}\right)\right]^{(-1 / \xi)-1} \exp \left\{-\left[1+\xi\left(\frac{x-\mu}{\sigma}\right)\right]^{-1 / \xi}\right\}
$$

in which $\xi$ is shape parameter, $\sigma$ is scale parameter and $\mu$ is location parameter. This model is used to sample the random extreme wave heights $H_{e, \text { crest }}$ and $H_{e, \text { cross }}$ conditional upon a value of $H_{s}$ determined from an MRP model. 

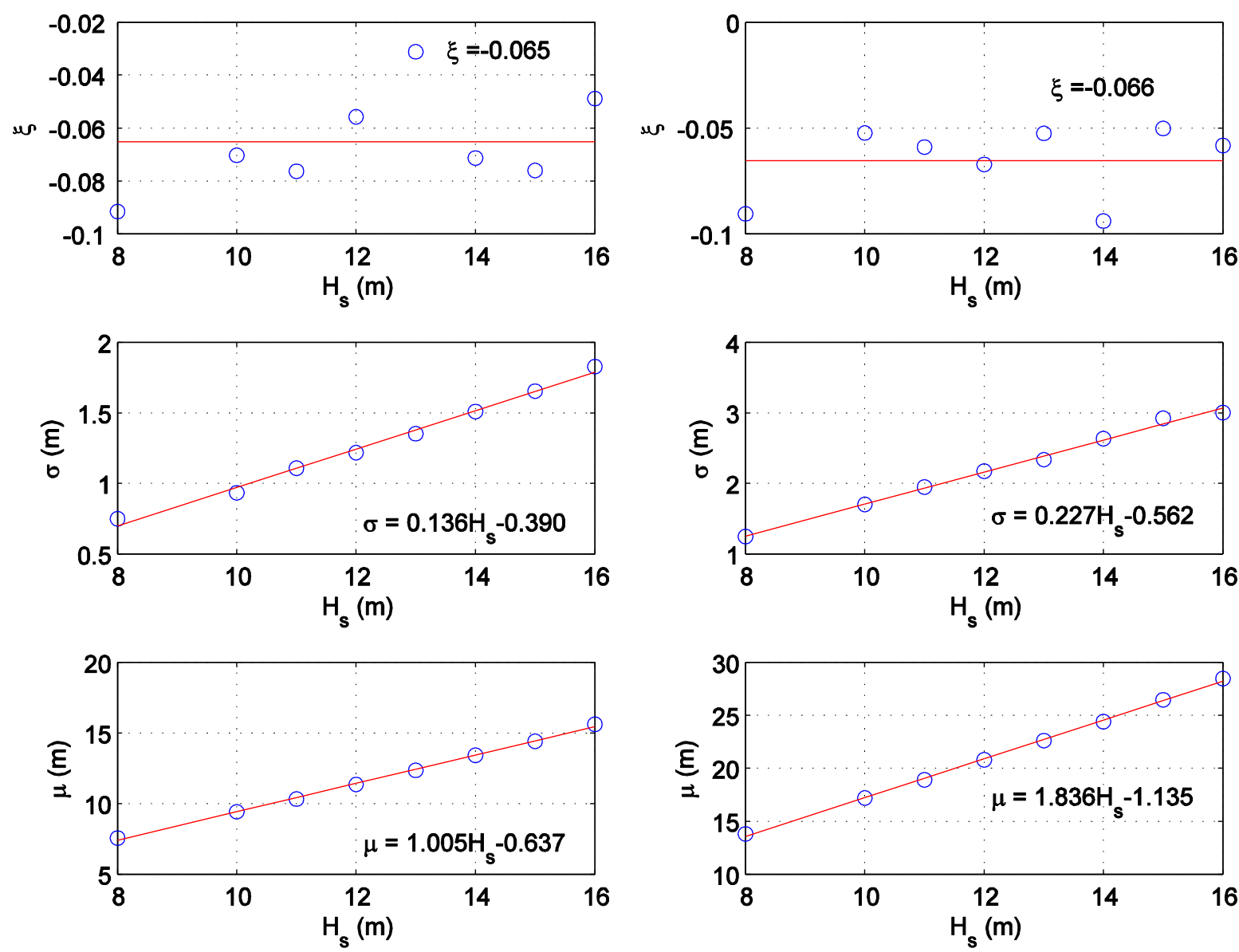

(a)

(b)

Figure 6 Proposed GEV probabilistic models for extreme crest height and extreme zeroup-crossing height: (a) GEV parameters for extreme crest height $C_{e}$ : shape parameter $\xi$, scale parameter $\sigma$ and location parameter $\mu$; (b) GEV parameters for extreme zero-upcrossing height $\boldsymbol{H}_{e, \text { cross }}$ : shape parameter $\xi$, scale parameter $\sigma$ and location parameter $\mu$.

Figure 6 shows the best-fit GEV parameters for the distributions of $C_{e}$ and $H_{e, \text { cross }}$ over a range of significant wave heights. Based on these results, the shape parameter $(\xi)$ is assumed independent of significant wave height and linear relationships are used for the scale $(\sigma)$ and location $(\mu)$ parameters, as indicated with red lines in Figure 6. $H_{e, \text { crest }}$ is the wave height of an isolated stream function wave with crest height equal to $C_{e}$ and can be calculated from $C_{e}$ according to Eq. (4). The shape parameter is assumed constant since the magnitude of the variation with wave height does not meaningfully affect the model distributions and associated variate levels and also because the results do not show a clear trend of evolution of the shape parameter with increasing wave height.

It should be noted at this point that wave breaking is not included in this study. Due to the deep water used in the example, even the extreme waves generated do not approach common breaking limits [26]. For such a study in shallower water, however, the possibility of wave breaking may have a significant influence on overall reliability and should be included, as it is in the co-authors' other work [38]. 


\subsection{Probabilistic extreme wind speed model}

The extreme wind speed $V_{e}$ is modeled probabilistically in a manner similar to the extreme wave heights $H_{e, c r e s t}$ and $H_{e, c r o s s}$. One thousand realizations of one-hour turbulent wind time histories are generated for a range of values of $V_{w}$, the 10-min hub height wind speed. The peak wind speed in the one hour history is assumed to be the 3 second gust. The Kaimal spectrum is used [39] with a turbulence intensity equal to $10 \%$ [40] [41].

The parameters of the GEV distribution for $V_{e}$ are presented in Figure 7 as a function of $V_{w}$. Best-fit linear regressions for the scale and location parameters are also shown. As with the extreme wave heights the shape parameter is assumed independent of wind speed and linear models are used for the scale and location parameters, as indicated with red lines in the Figure 7. Note that although a linear trend is evident in $\xi$, the range is very small (-0.09 to $0.105)$ and covers a range of values that does not significantly affect the underlying distributions and associated variate levels.
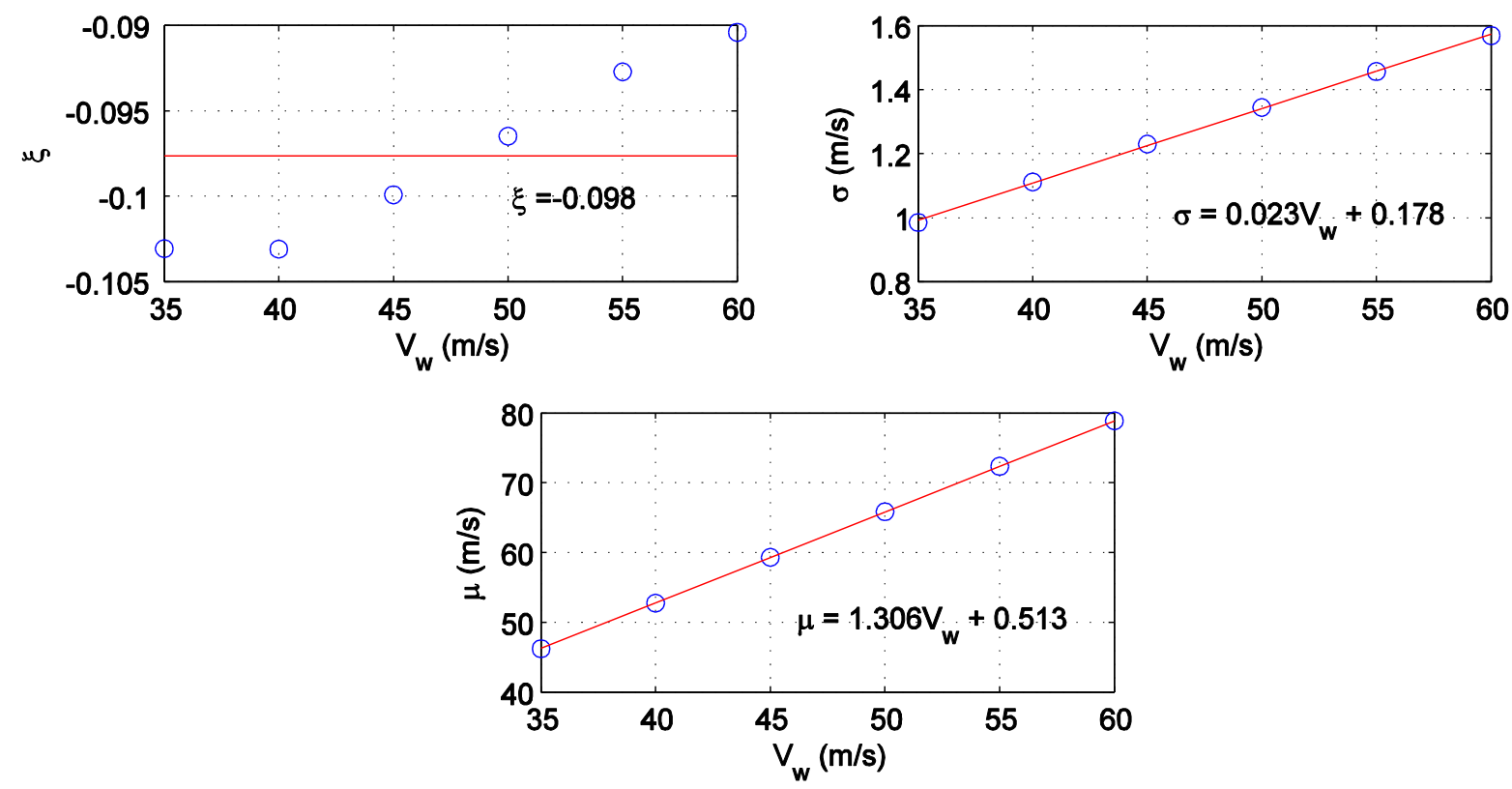

Figure 7 Proposed GEV probabilistic models for extreme wind speed: GEV parameters: shape parameter $\xi$, scale parameter $\sigma$ and location parameter $\mu$ for extreme wind speed. Note that although a linear trend is evident in $\xi$, the range is very small $(-0.09$ to -0.105$)$ and this linear trend is therefore neglected without meaningful impact on the shape of the GEV distributions.

\subsection{Probabilistic model of structural material}

The offshore jacket in this study is assumed to be made of ASTM A572 Grade 50 steel with a nominal yield strength of $345 \mathrm{MPa}$ with a coefficient of variation of $6 \%$ [42]. According to the DNV guideline for offshore structural reliability [43], nominal yield strength is defined by the $5 \%$ quantile of test data assuming a lognormal distribution. The mean yield strength $F_{y}$ is therefore $381 \mathrm{MPa}$ with a standard deviation of $23 \mathrm{MPa}$. The plastic hinge model used here neglects material hardening beyond the yield stress, using a tri-linear approximation to moment-rotation response that has changes in stiffness at the yield and plastic moments and assumes perfectly plastic behavior beyond the plastic moment. Therefore the yield stress and elastic modulus completely characterize the material properties and here the elastic modulus is assumed deterministic with a value of $210 \mathrm{GPa}$. 


\subsection{Definition of performance levels}

Three performance levels corresponding to three damage states are defined in Figure 8: i) operational and undamaged, ii) non-operational and damaged and iii) near collapse and severely damaged. Two fragility functions, representing the initiation of damage and the ultimate strength of the structure, are used to delimit the performance levels and damage states. Here, the initiation of damage is defined as the first yield of any member in the structure under combined axial and bending effects and the ultimate strength is defined as the formation of a plastic collapse mechanism in the structure. The performance levels here apply only to the support structure below the rotor-nacelle-assembly and inclusion of the blades, soil and electromechanical systems of the nacelle would require a more nuanced treatment of performance levels and damage states, likely resulting in more performance levels.

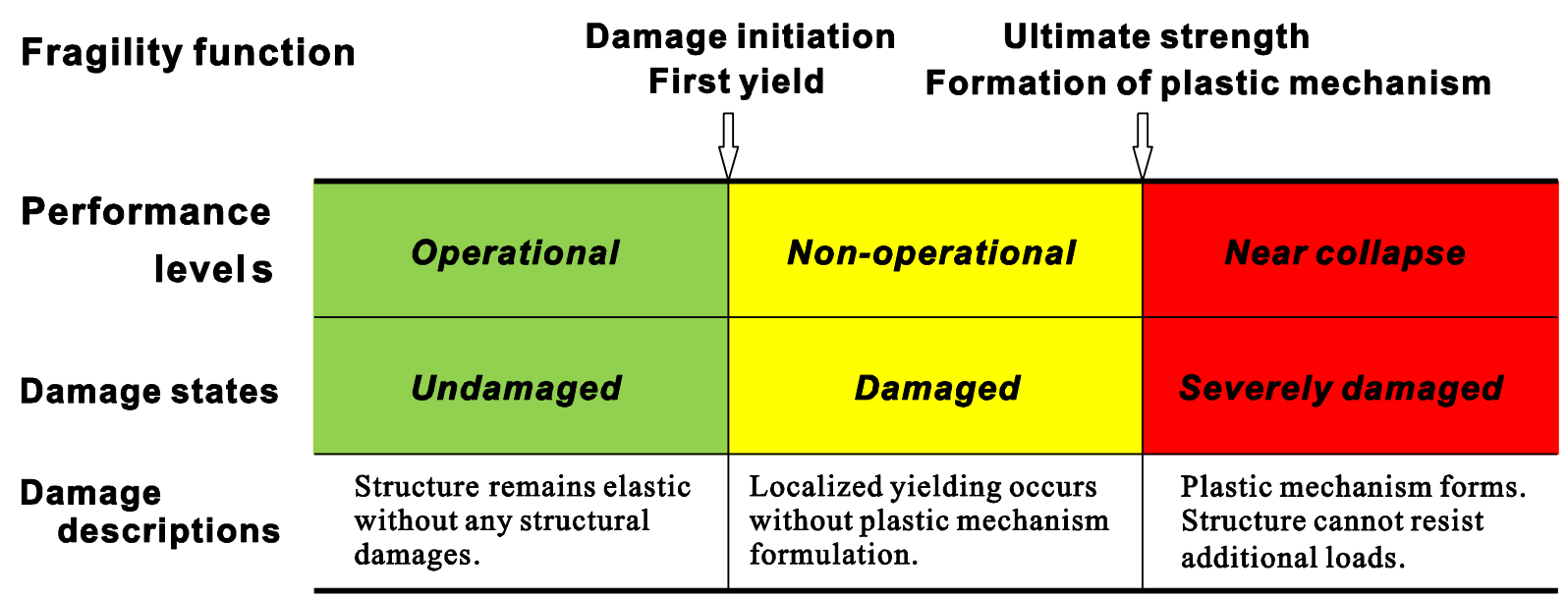

Figure 8 Proposed performance levels and corresponding damage states of an OWT supported by a jacket based on pushover analysis.

\subsection{Prediction of demand}

Given values of $H_{e, \text { crest }}$ or $H_{e, \text { cross }}$ and $V_{e}$ sampled from the appropriate distributions, the demand on the structure can be obtained. The aerodynamic forces on the OWT are determined with the aid of the computer-aided engineering tool FAST [44] for the rotor and the recommendations of the DNV specification [45] for the tower. In both cases a steady wind at speed $V_{e}$ is assumed and the rotor is parked and the blades are feathered to reflect the extreme conditions. The wind speed is assumed to vary with height above sea level according to a power law with a wind shear exponent of 0.14 . This wind shear profile is taken from recommendations in IEC [2] and does not consider hurricane conditions specifically. Hurricane-specific wind shear profile models [46] can represent expected wind shear conditions during hurricanes more accurately. Hydrodynamic loads on the submerged part of the jacket are calculated using a nonlinear stream function approximation of tenth or higher order to compute water particle velocity and acceleration through the depth of the water column and Morison's equation to compute drag and inertial forces on the structural members assuming long crested waves and co-directional wind and wave conditions. Wave force on the jacket is drag dominated due to the slender member dimensions, meaning that peak loads are achieved when water particles pass the structure with maximum velocity (i.e., each location on each member experiences maximum hydrodynamic load at the moment when the wave crest passes that location). To simplify the load calculation a conservative assumption has been made that all member forces correspond to those generated by wave crest kinematics. This assumption neglects the relative length scales of the wavelength and 
jacket structure but, certainly for more advanced dynamic analyses, such spatio-temporal variation of wave loading over the plan dimensions of the structure and fluid-structure interaction, should be revisited. For extreme environmental conditions when the wave crest contacts the deck, a Morison-type approach is used to calculate the so-called wave-in-deck force generated by this interaction [16].

The summation of the lateral components of all of the above forces (aerodynamic forces on rotor and tower and hydrodynamic forces on the jacket and deck) equals the demand base shear of the sample. Demand is a function of $H_{e, \text { crest }}$ or $H_{e, \text { cross }}$ and $V_{e}$ and jacket geometry. Figure 9 shows the demand surface $D\left(H_{e}, V_{e}\right)$ for the example considered here, and it is observed that the total base shear demand is dominated by $H_{e}$ and relatively insensitive to $V_{e}$. For example, at a hurricane-based MRP of 200 years, the mean $H_{e, \text { cross }}$ is $29.0 \mathrm{~m}$ and the mean $V_{e}$ is $84.1 \mathrm{~m} / \mathrm{s}$. For these conditions, the total base shear is nearly $30,000 \mathrm{kN}$, of which $5 \%$ is due to wind loading and $95 \%$ is due to wave loading. Such dominance of the wave loading on the base shear stems from several sources. First, since base shear rather than base moment is used to quantify the demand the additional moment arm associated with the wind forces on the tower and rotor does not affect the relative importance of wind and wave to the demand. Second, the analysis presented here considers only non-operational cases in which the rotor blades are parked, feathered and perfectly yawed into the wind, thereby minimizing aerodynamic loads. Third, wave-in-deck forces are significant for very large waves (crest height $=16.1 \mathrm{~m}$ corresponding to a wave height of $24.5 \mathrm{~m}$ ) due to the design of the UPWIND jacket, which has a thick solid concrete deck. The wave height at which wave-in-deck force occurs is shown in Figs. 9 and 10.

A demand surface is used in the following section to efficiently determine the demand on the jacket for arbitrary wind and wave conditions. The demand model as presented here is independent of the extreme wave modeling approach provided that when using Figure $9, H_{e}=$ $H_{e, \text { cross }}$ when the zero-up-crossing model is used and $H_{e}=H_{e, \text { crest }}$ is used when the extreme crest height model is used. The demand as shown is based on a static analysis of the structural response to wind and wave loads. Dynamic effects are potentially important and are a subject of current investigation by the authors. For the particular characteristics of the UPWIND jacket, it is found that the dynamic amplification factor for regular, periodic, waves large enough to cause structural damage is small. This effect has been neglected here resulting in slightly lower estimates of the probability of damage.

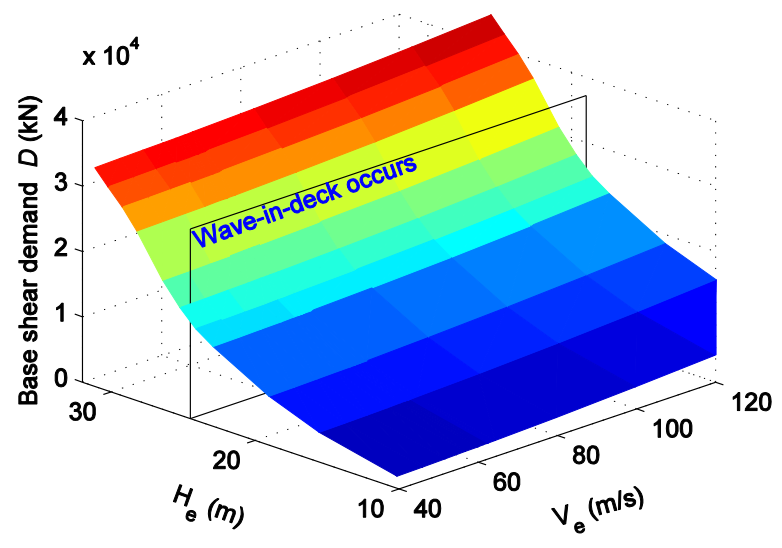

Figure 9 Base shear demand surface for Massachusetts site as a function of $V_{e}$ and $H_{e}$. The vertical plane indicates the extreme wave height $H e$ when the wave first contacts the deck. 


\subsection{Prediction of structural capacity}

Once the yielding strength $F_{y}$, extreme wave height $H_{e}$ and extreme wind speed $V_{e}$ of each sample are drawn from their respective distributions, the base shear capacity corresponding to first yield $\left(C_{1}\right)$ and plastic mechanism formation $\left(C_{2}\right)$ can be calculated using a static pushover analysis. Here, the pushover analysis is performed in the commercial code SAP2000 and details of the analysis methods are given in Section 3.1. Plastic mechanism formation primarily involves the leg members in the bottom two levels of the jacket. It is important to note that the base shear capacities depend on the environmental conditions $H_{e}$ and $V_{e}$ since the load pattern depends on those parameters, particularly the wave height [16]. To make fragility computations more efficient, a response surface approach is used here to predict $C_{1}$ and $C_{2}$ as a function of wind speed, wave height, and material yield strength. These surfaces roughly correspond to the 2-parameter Incremental Wind Wave Analysis surfaces introduced in [16] and are calculated using a structure with nominal yield strength $F_{y, 0}=345 \mathrm{MPa}$. Figure 10 shows the $C_{l}\left(H_{e}, V_{e}, F_{y, 0}\right)$ and $C_{2}\left(H_{e}, V_{e}, F_{y, 0}\right)$ response surfaces. The capacity surfaces are independent of extreme wave modeling approach, similar to the demand model.

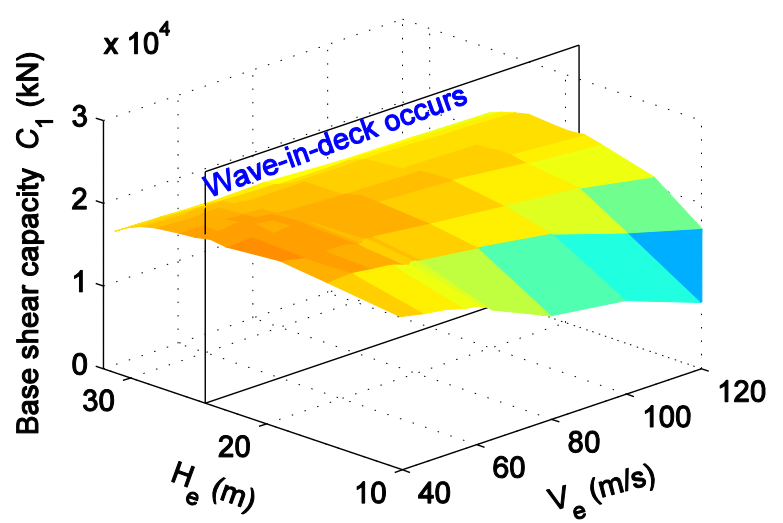

(a)

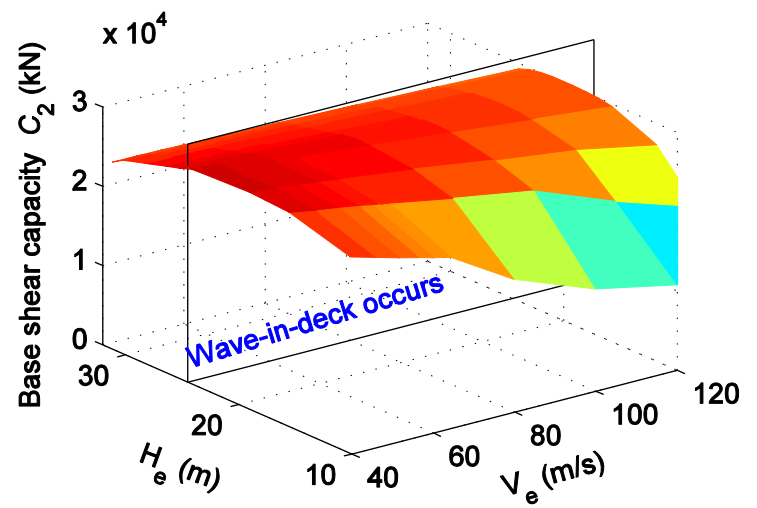

(b)

Figure 10 Capacity surfaces as a function of $V_{e}$ and $H_{e}$ for $F_{y, 0}=345 \mathrm{Mpa}$. (a) Capacity C1: first yielding; (b) Capacity $C_{2}$ : plastic mechanism formation. The vertical plane indicates the He when the wave first contacts the deck.

Since the fragility analysis presented here incorporates uncertainty in the material yield stress, a method is required for accounting for yield stress variation in the response surface. Through a series of pushover analyses of the jacket structure across a range of yield strengths, the capacities $C_{1}$ and $C_{2}$ are found to have a linear dependence on $F_{y}$ that is accurate over a range of values of $F_{y}$ corresponding to \pm 2 standard deviations, meaning that the response surfaces of Figure 10 can be scaled linearly with the yield stress according to,

$$
\begin{aligned}
& C_{1}\left(F_{y}\right)=C_{1}\left(F_{y, 0}\right)+59.3\left(F_{y}-F_{y, 0}\right) \\
& C_{2}\left(F_{y}\right)=C_{2}\left(F_{y, 0}\right)+65.6\left(F_{y}-F_{y, 0}\right)
\end{aligned}
$$

in which $C_{i}\left(F_{y, 0}\right), i=1,2$, represent the capacities for a structure with nominal $F_{y, 0}$. Note that the constants in Eqs. (6) and (7) are not dimensionless and units of $\mathrm{kN}$ (for $\mathrm{C}_{1}$ and $\mathrm{C}_{2}$ ) and $\mathrm{MPa}$ (for $\mathrm{F}_{\mathrm{y}}$ and $\mathrm{F}_{\mathrm{y}, 0}$ ) must be used. 


\section{RESULTS AND DISCUSSION}

Given the probabilistic models for extreme wave height $H_{e}$, extreme wind speed $V_{e}$, and yield stress $F_{y}$, along with the response surfaces for demand $D\left(H_{e}, V_{e}\right)$, first yield capacity $C_{l}\left(H_{e}, V_{e}\right.$, $\left.F_{y}\right)$, and ultimate capacity $C_{2}\left(H_{e}, V_{e}, F_{y}\right)$, the estimate of probabilities of damage for the example jacket is conducted based on Monte Carlo simulation. Curves of probability of damage versus MRP are constructed for the four possible combinations of extreme wave model (crest height or zero-up-crossing height) and environmental condition model (NOAA or hurricane).

When the demand base shear $D\left(H_{e}, V_{e}\right)$, first yield capacity $C_{l}\left(H_{e}, V_{e}, F_{y}\right)$, and plastic mechanism capacity $C_{2}\left(H_{e}, V_{e}, F_{y}\right)$ are obtained for all the samples of the triplet of random variables $\left(H_{e}, V_{e}, F_{y}\right)$ at the given MRP, the probability of damage with respect to first yield $P_{f, I}(M R P)$ and plastic mechanism $P_{f, 2}(M R P)$ can be determined by Eqs. (8) and (9),

$$
\begin{aligned}
& P_{f, 1}\left(M R P_{j}\right)=P\left[C_{1} \leq D \mid I M=M R P_{j}\right] \\
& P_{f, 2}\left(M R P_{j}\right)=P\left[C_{2} \leq D \mid I M=M R P_{j}\right]
\end{aligned}
$$

Note that in the above equations MRP is used as a surrogate for IMs of wind speed and wave height, a treatment of IM that is somewhat unusual but allows the IM to be treated as a scalar. Figure 11 shows the estimate of the probability of damage the example structure as a function of the MRP of the environmental conditions based on $n_{s}=1000$ random samples of $H_{e}, V_{e}$, and $F_{y}$ at each value of the IM (MRP).

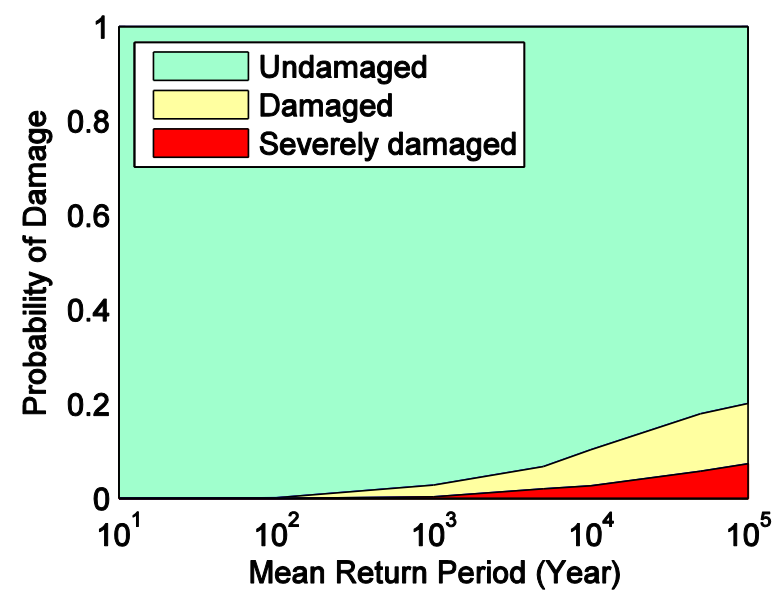

(a) $H_{e, \text { crest }} / \mathrm{NOAA}$

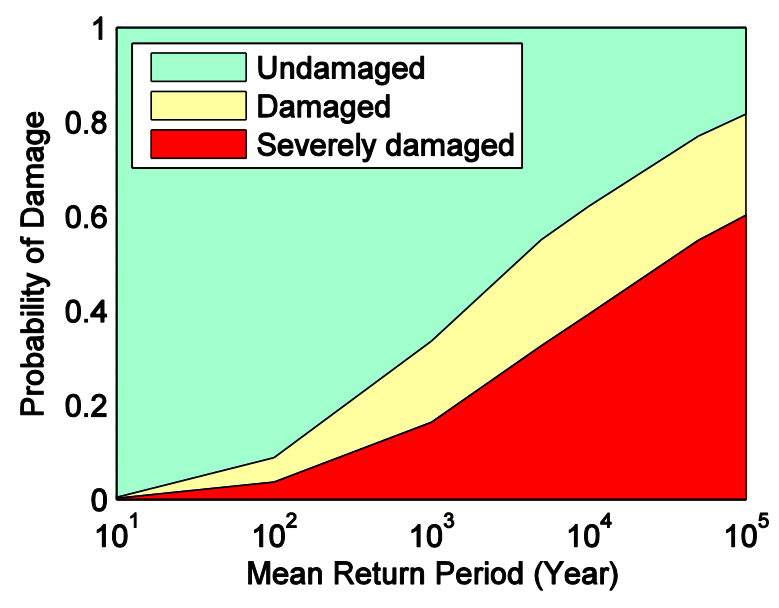

(b) $H_{e, \text { cross }} / \mathrm{NOAA}$ 


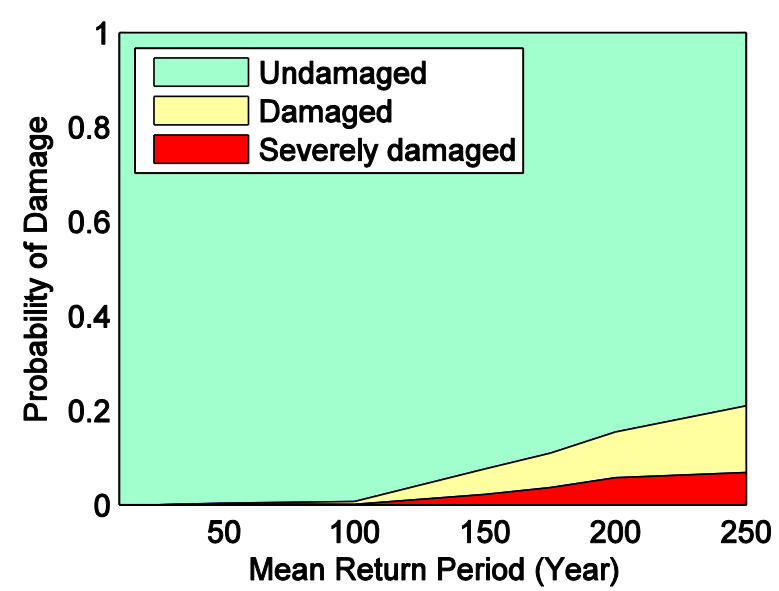

(c) $H_{e, \text { crest }} /$ hurricane

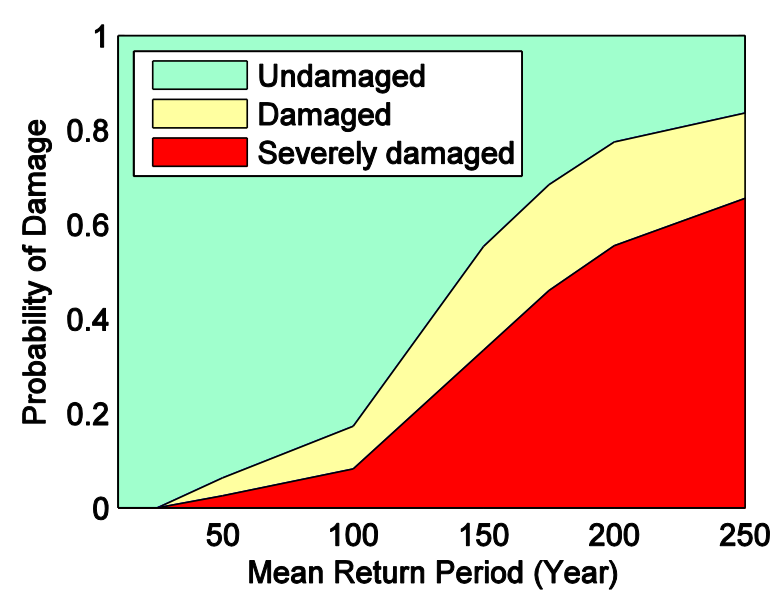

(d) $H_{e, \text { cross }} /$ hurricane

Figure 11 Probabilities of damage for three damage states (undamaged in green, damaged in yellow and severely damaged in red) corresponding to three performance levels (operational, non-operational and near collapse) for an example OWT supported by a jacket under NOAA and hurricane wind and wave loading and for two models, $H_{e, \text { crest }}$ and $H_{e, \text { cross, }}$ for the extreme wave height.

In interpreting the probabilities of damage, it is important to note that the range of MRP values used for analysis based on the NOAA and hurricane environmental models differs by three orders of magnitude. This reflects the drastically different hazard estimates developed from the NOAA and hurricane datasets and is a critically important consideration since any attempt to assess overall risk to an OWT will depend on the wind and wave conditions associated with extreme events and long MRPs. For design, typically based on 50-year conditions, the difference in the probability of damage between the NOAA and hurricane data is much smaller. Figure 2 shows that MRP values of 100,000 (NOAA) and 250 years (hurricane) correspond to essentially identical significant wave heights and wind speeds that are somewhat higher for the hurricane model. Since the response of the jacket structure in this example is wave dominated, the environmental conditions at 100,000 years (NOAA) and 250 years (hurricane) are essentially equivalent and result in similar fragilities. Nevertheless, the probabilities of damage in Figures 11b and 11d and in 11a and 11c do differ, with the probabilities based on the hurricane environmental model rising more steeply than those based on the NOAA model. The enormous difference in MRP corresponding to equivalent probability of damage obtained from the NOAA and hurricane models would result in markedly different assessments of performance and risk, and this study therefore illustrates the importance of incorporating hurricane data (measured or synthetic) into estimates of the environmental hazard. Comparison of Figures $11 \mathrm{a}$ and $11 \mathrm{~b}$ and $11 \mathrm{c}$ and $11 \mathrm{~d}$ illustrates the sensitivity of the probability of damage to the wave height model. The differences in demand generated by the different extreme wave models is caused by two factors: the demand is highly sensitive to whether the wave crest reaches the elevation of the deck resulting in potentially large wave-in-deck forces; the hydrodynamic load as calculated by the Morison equation depends on the square of the fluid particle velocity which will differ at different elevations between the two extreme wave models. The first effect, wave-in-deck force, is the dominant cause of sensitivity to extreme wave model. For these reasons, the probability of damage is significantly higher when modeling extreme waves with $H_{e, \text { cross }}$ instead of $H_{e, \text { crest }}$. Figure 5 provides a graphical explanation of why probabilities of damage are higher for $H_{e, \text { cross }}$ than $H_{e, \text { crest }}$, namely that when $H_{e, \text { cross }}$ is used as the extreme wave variable, stream 
function theory generates isolated waves with crest heights that are larger than are present in the irregular wave trains. On the contrary, if $H_{e, c r e s t}$ is used to characterize the height of the extreme wave in an irregular wave train, the corresponding isolated wave has exactly the correct crest height, although the crest-to-trough height of such a wave may be smaller than the corresponding wave in the irregular wave train. Partially due to the importance of wavein-deck forces for the structure considered here, the crest height is the most important wave parameter to match correctly.

It is worth recalling at this point several of the assumptions and simplifications made in the analysis leading to Figure 11: (1) For the NOAA environmental model, the severity of the conditions is likely underestimated due to the relatively short duration of the measurement history; (2) Also for the NOAA model, the independent combination of wind and wave annual maxima as well as assuming $V_{e}$ and $H_{e}$ being temporally coincident overestimate the hazard; (3) Failure and damage modes other than member yielding are neglected, although geometric nonlinear modeling of the structure means that such yielding could be brought on by member buckling; (4) The jacket used here was designed for a site at which hurricanes are not present, meaning that, while comparisons between the probabilities of damage provide valid insights, the numerical values of the probabilities should not be taken to be accurate representations of a design made for this specific site; (5) Dynamic effects are neglected; (6) Some modeling idealizations (fixed base, rigid joints, one-dimensional wave and regular wave kinematics, etc.) are adopted. These assumptions and simplifications affect the shape and magnitude of the probabilities of damage shown in Figure 11, however, they do not affect the framework by which these probabilities were derived as a basis for performance assessment of OWTs supported by jackets. Refinements related to these assumptions and simplifications constitute the core of an ongoing research program to develop a total performance assessment strategy for offshore wind farms. Future work will be determined based on the potential of specific refinements to affect assessments like the example provided above.

Some further discussion of assumption (3), that the only member failure mode is member yielding and plasticity, is warranted. For tubular steel members and their connections, global and local buckling failure modes and the fracture failure mode, as well as punch through and pullout of the brace should be considered [47-49]. Members in the example jacket used here are compact, meaning that the section can sustain the plastic moment before local failure, or within 5\%-10\% of the compactness limits [50] in terms of slenderness. Sufficient discretization, typically 8 elements per member, has been used such that the geometric nonlinearity within the pushover analysis should capture member buckling [51], and such behavior was not observed.

For joint failure modes, the literature presents a range of empirical and semi-empirical equations to predict joint strength considering a wide range of failure modes. Marshall and Toprac [52] performed experiments to analyze a simple joint suffering from brace punchthrough failure. Yura [53] proposed capacity equations for four types of tubular joint geometry based on a series of 137 joint strength tests. Kurobane et al. [54, 55] and Paul et al. [56] studied unstiffened TT and KK joint geometries under symmetric and anti-symmetric brace axial forces. Kurobane et al. [57] proposed simple equations for resistance and deformation capacity of joints suffering from brace buckling. Kiuchi et al. [58] investigated the behavior of KTKT joints based on laboratory testing and proposed a predictive equation for the ultimate capacity of the joints.

The above experimental investigations have been supplemented with simulation-based studies that account for geometric and material nonlinearity and, in some cases, fracture [59- 
62] and such simulation studies have led to capacity prediction equations for multi-planar tubular joints for geometries and load conditions beyond the range of parameters considered in the experimental studies $[63,64]$. There are significant challenges in applying these equations to the jacket structure considered here, among which are mismatch between the geometry of the test specimens and the jacket and issues of symmetry/anti-symmetry and moment-axial force interaction in the member forces that are typically not covered in the experimental or simulation studies. Despite these challenges, joint capacities have been calculated using all available predictive equations and have been found to closely match or exceed demand on the joints at the formation of a plastic collapse mechanism. Therefore, such additional joint failure modes have been neglected here.

\section{CONCLUSION}

In this study, a framework for performance and risk assessment of offshore jacket structures intended to support wind turbines under extreme wind and wave loading is presented and illustrated by application to an example jacket structure located at a site off the coast of Massachusetts. The framework consists of probabilistic models for the wind speed and wave heights as well as material property uncertainty static pushover analysis to assess the capacity of the jacket structure. Two environmental models are used, one corresponding to extrapolation of 30 years of NOAA data buoy measurements and one to a stochastic hurricane catalog, and two models for extreme wave height are also used, one that models the extreme crest height and one that models the extreme zero-up-crossing (crest-to-trough) height. Two curves of probability of damage (representing the occurrence of first yield and plastic mechanism formation) delineating three performance levels (operational, nonoperational and near collapse) and damage states (undamaged, damaged, and severely damaged) are proposed and probabilities of damage are calculated based on Monte Carlo simulations using response surfaces for the structural capacity subject to random wind and wave conditions and random material properties. The probabilities of damage are highly sensitive to the environmental and wave height model used. Regarding the environmental model, calculating environmental conditions based on a stochastic catalog of synthetic hurricanes is found to greatly increase the probability of damage compared to calculating environmental conditions by extrapolating a limited period of data. Regarding the wave height model, the probability of damage is highly sensitive to the wave modeling approach. Much higher probabilities are found when modeling extreme waves with $H_{e, \text { cross }}$ instead of $H_{e, \text { crest }}$, though it should be noted that this effect is caused by transformation of the wave height variables from the irregular wave train to characteristics of an isolated wave. It has been common practice to use the zero-up-crossing wave height as a measure of extreme wave height and using this model in the current performance-based evaluation framework would potentially overestimate the probability of damage and therefore risk. It should be noted, however, that the importance of modeling wave crest height correctly is largely due to the importance of wave-in-deck forces on the jacket structure considered here, which has a thick, solid deck structure. Such a deck may not prove to be typical for forthcoming offshore wind structures. Therefore, this conclusion regarding the conservatism of wave height models may not apply generally to broad classes of offshore structures and care should be taken in applying it to specific design examples. The approach presented here can be used as part of a complete performance assessment for offshore structures, if models for the financial consequences of reaching various damage states are developed. 


\section{ACKNOWLEDGEMENT}

This work was supported financially by the US National Science Foundation (NSF) through Grants 1234560 and 1234656 and by the Massachusetts Clean Energy Center (MassCEC). Vahid Valamanesh at Northeastern University provided assistance in the modeling of environmental conditions. Any opinions, findings, and conclusions or recommendations expressed in this material are those of the authors and do not necessarily reflect the view of the National Science Foundation or other funding agencies.

\section{REFERENCES}

[1] J.F. Manwell, A.L. Rogers, J.G. McGowan, B.H. Bailey, An offshore wind resource assessment study for New England, Renew Energ, 27 (2002) 175-187.

[2] International Electrotechnical Commission, Wind Turbines - Part 3: Design Requirements for Offshore Wind Turbines, IEC 61400-3, in, 2009.

[3] S. Rose, P. Jaramillo, M.J. Small, I. Grossmann, J. Apt, Quantifying the hurricane risk to offshore wind turbines, Proceedings of the National Academy of Sciences, 109 (2012) 32473252 .

[4] K. Kinali, B.R. Ellingwood, Seismic fragility assessment of steel frames for consequencebased engineering: A case study for Memphis, TN, Eng Struct, 29 (2007) 1115-1127.

[5] C. Kafali, M. Grigoriu, Seismic fragility analysis, in: Proceedings of the Ninth ASCE Specialty Conference on Probabilistic Mechanics and Structural Reliability (PMC2004), 2004.

[6] J.E. Padgett, R. DesRoches, Methodology for the development of analytical fragility curves for retrofitted bridges, Earthquake Engineering \& Structural Dynamics, 37 (2008) 1157-1174.

[7] E. Nuta, C. Christopoulos, J.A. Packer, Methodology for seismic risk assessment for tubular steel wind turbine towers: application to Canadian seismic environment, Canadian Journal of Civil Engineering, 38 (2011) 293-304.

[8] A. Myers, A. Gupta, C. Ramirez, E. Chioccarelli, Evaluation of the Seismic Vulnerability of Tubular Wind Turbine Towers, in: the 15th World Conference on Earthquake Engineering, 24-28 September, Lisbon, Portugal, 2012.

[9] D.H. Kim, S.G. Lee, I.K. Lee, Seismic fragility analysis of 5 MW offshore wind turbine, Renew Energ, 65 (2014) 250-256.

[10] M. Ciampoli, F. Petrini, Performance-Based Design of Offshore Wind Turbines, in: Earth and Space 2010, American Society of Civil Engineers, 2010, pp. 2063-2078.

[11] A. Quilligan, A. O'Connor, V. Pakrashi, Fragility analysis of steel and concrete wind turbine towers, Eng Struct, 36 (2012) 270-282.

[12] M. Mardfekri, P. Gardoni, Probabilistic demand models and fragility estimates for offshore wind turbine support structures, Engineering Structures, 52 (2013) 478-487.

[13] P.W. Cheng, G.J.W. van Bussel, G.A.M. van Kuik, J.H. Vugts, Reliability-based design methods to determine the extreme response distribution of offshore wind turbines, Wind Energy, 6 (2003) 1-22.

[14] M.B. Fallon, A Probabilistic Deformation Demand Model and Fragility Estimates for Asymmetric Offshore Jacket Platforms, in: Texas A\&M University, 2012. 
[15] A.A. Taflanidis, E. Loukogeorgaki, D.C. Angelides, Offshore wind turbine risk quantification/evaluation under extreme environmental conditions, Reliab Eng Syst Safe, 115 (2013) 19-32.

[16] K. Wei, S.R. Arwade, A.T. Myers, Incremental wind-wave analysis of the structural capacity of offshore wind turbine support structures under extreme loading, Engineering Structures, 79 (2014) 58-69.

[17] K. Mackie, B. Stojadinović, R -Factor Parameterized Bridge Damage Fragility Curves, Journal of Bridge Engineering, 12 (2007) 500-510.

[18] K.E. Steele, T. Mettlach, NDBC wave data-current and planned, in: Ocean Wave Measurement and Analysis, ASCE, 1993, pp. 198-207.

[19] F. Liu, W. Pang, Influence of Climate Change on Future Hurricane Wind Hazards along the US Eastern Coast and the Gulf of Mexico, in: Advances in Hurricane Engineering, 2012, pp. 573-584.

[20] V. Valamanesh, A. Myers, J. Hajjar, S. Arwade, Probabilistic Modeling of Joint Hurricane-induced Wind and Wave Hazards to Offshore Wind Farms on the Atlantic Coast, in: 11th International Conference on Structural Safety \& Reliability., New York, NY, 2013.

[21] V. Valamanesh, Probabilistic hazard analysis of extreme environmental conditions for offshore wind turbines, in: Department of Civil and Envrionmental Engineering, Northeastern University, 2015.

[22] G.J. Holland, An Analytic Model of the Wind and Pressure Profiles in Hurricanes, Mon Weather Rev, 108 (1980) 1212-1218.

[23] I.R. Young, Parametric Hurricane Wave Prediction Model, J Waterw Port C-Asce, 114 (1988) 637-652.

[24] M. Mizuguchi, Individual wave analysis of irregular wave deformation in the nearshore zone, Coastal Engineering, 1 (1982) 485-504.

[25] R.G. Dean, Stream Function Representation of Nonlinear Ocean Waves, J Geophys Res, 70 (1965) 4561-4572.

[26] B. Le Mehaute, An introduction to hydrodynamics and water waves, Springer Science \& Business Media, 2013.

[27] J.D. Fenton, The numerical solution of steady water wave problems, Computers \& Geosciences, 14 (1988) 357-368.

[28] J.M. Jonkman, S. Butterfield, W. Musial, G. Scott, Definition of a 5-MW reference wind turbine for offshore system development, in, National Renewable Energy Laboratory Colorado, 2009.

[29] F. Vorpahl, W. Popko, D. Kaufer, Description of a basic model of the" UpWind reference jacket" for code comparison in the OC4 project under IEA Wind Annex XXX, Fraunhofer Institute for Wind Energy and Energy System Technology (IWES), 4 (2011) 1-14.

[30] W.-F. Chen, I. Sohal, Plastic design and second-order analysis of steel frames, SpringerVerlag, New York, 1995.

[31] E. Simiu, Design of buildings for wind: a guide for ASCE 7-10 standard users and designers of special structures, 2nd ed., John Wiley \& Sons, Inc., 2011. 
[32] M.D. Powell, P.J. Vickery, T.A. Reinhold, Reduced drag coefficient for high wind speeds in tropical cyclones, Nature, 422 (2003) 279-283.

[33] P. Agarwal, L. Manuel, Incorporating irregular nonlinear waves in coupled simulation and reliability studies of offshore wind turbines, Applied Ocean Research, 33 (2011) 215-227.

[34] K. Hasselmann, T. Barnett, E. Bouws, H. Carlson, D. Cartwright, K. Enke, J. Ewing, H. Gienapp, D. Hasselmann, P. Kruseman, Measurements of wind-wave growth and swell decay during the Joint North Sea Wave Project (JONSWAP), in, 1973.

[35] V. Valamanesh, A.T. Myers, S.R. Arwade, J.F. Hajjar, The Impact of Peak Spectral Period in the Design of Offshore Wind Turbines for the Extreme Sea State, in, ASCE, 2014, pp. 1684-1693.

[36] M.D. Earle, Extreme wave conditions during Hurricane Camille, J Geophys Res, 80 (1975) 377-379.

[37] E.S. Martins, J.R. Stedinger, Generalized maximum-likelihood generalized extremevalue quantile estimators for hydrologic data, Water Resour Res, 36 (2000) 737-744.

[38] S. Hallowell, A.T. Myers, S.R. Arwade, Variability of breaking wave characteristics and impact loads on offshore wind turbines supported by monopiles, Wind Energy, 16 (2016) 301-312.

[39] International Electrotechnical Commission, Wind Turbines - Part 1: Design Requirements, IEC 61400-1, in, 2005.

[40] B. Lange, H.P. Waldl, A.G. Guerrero, D. Heinemann, R.J. Barthelmie, Modelling of offshore wind turbine wakes with the wind farm program FLaP, Wind Energy, 6 (2003) 87104.

[41] J.P. Coelingh, A.J.M. van Wijk, J.W. Cleijne, R. Pleune, Description of the North Sea wind climate for wind energy applications, Journal of Wind Engineering and Industrial Aerodynamics, 39 (1992) 221-232.

[42] J. Billingham, J. Sharp, J. Spurrier, P. Kilgallon, Review of the performance of high strength steels used offshore, in: Health Saf. Exec, 2003.

[43] R. Skjong, E. Bitner-Gregersen, E. Cramer, A. Croker, Ø. Hagen, G. Korneliussen, S. Lacasse, I. Lotsberg, F. Nadim, K. Ronold, Guidelines for offshore structural reliability analysis-General, in: DNV Report No. 95-2018, 1995.

[44] J.M. Jonkman, M.L. Buhl Jr, FAST user's guide, in, Golden, CO: National Renewable Energy Laboratory, 2005.

[45] Det Norske Veritas, Environmental conditions and environmental loads, in: DNV-RPC205, DNV, 2010.

[46] W.M. Frank, E.A. Ritchie, Effects of vertical wind shear on the intensity and structure of numerically simulated hurricanes, Mon Weather Rev, 129 (2001) 2249-2269.

[47] Energo Engineering Inc., Assessment of Fixed Offshore Platform Performance in Hurricanes Andrew, Lili and Ivan, in, 2005.

[48] Energo Engineering Inc., Assessment of Fixed Offshore Platform Performance in Hurricanes Katrina and Rita, in, 2007.

[49] Energo Engineering Inc., Assessment of Damage and Failure Mechanisms for Offshore Structures and Pipelines In Hurricanes Gustav And Ike, in, 2010. 
[50] American Institute of Steel Construction, Load and Resistance Factor Design Specification for Steel Hollow Structural Sections, in, Chicago, Illinois, 2000.

[51] D.W. White, J.F. Hajjar, Application of second-order elastic analysis in LRFD: research to practice, Engineering Journal, 28 (1991) 133-148.

[52] P. Marshall, A. Toprac, Basis for tubular joint design, Welding Journal, 53 (1974) 192201.

[53] J.A. Yura, N.A. Zettlemoyer, I.F. Edwards, Ultimate Capacity Equations for Tubular Joints, in: Offshore Technology Conference, Offshore Technology Conference, 1980.

[54] Y. Kurobane, Y. Makino, K. Ochi, Ultimate Resistance of Unstiffened Tubular Joints, Journal of Structural Engineering, 110 (1984) 385-400.

[55] Y. Kurobane, Static Behaviour and Earthquake Resistant Design of Welded Tubular Structures, in: Mechanics and Design of Tubular Structures, Springer, 1998.

[56] J.C. Paul, Y. Makino, Y. Kurobane, Ultimate Resistance of Unstiffened Multiplanar Tubular Tt-Joints and Kk-Joints, Journal of Structural Engineering, 120 (1994) 2853-2870.

[57] Y. Kurobane, K. Ogawa, K. Ochi, Y. Makino, Local Buckling of Braces in Tubular KJoints, Thin-Walled Structures, 4 (1986) 23-40.

[58] T. Kiuchi, Y. Makino, Y. Kurobane, Static tests of axially loaded CHS KTKT-joints, in: The Tenth International Offshore and Polar Engineering Conference, International Society of Offshore and Polar Engineers, 2000.

[59] M.M.K. Lee, Strength, stress and fracture analyses of offshore tubular joints using finite elements, J Constr Steel Res, 51 (1999) 265-286.

[60] A.S. Elnashai, W. Aritenang, Nonlinear Modeling of Weld-Beaded Composite Tubular Connections, Eng Struct, 13 (1991) 34-42.

[61] M. Lee, S. Wilmshurst, Strength of multiplanar tubular KK-joints under antisymmetrical axial loading, Journal of Structural Engineering, 123 (1997) 755-764.

[62] X.D. Qian, Y. Zhang, Y.S. Choo, A load-deformation formulation for CHS X- and Kjoints in push-over analyses, J Constr Steel Res, 90 (2013) 108-119.

[63] B. Wang, N. Hu, Y. Kurobane, Y. Makino, S.T. Lie, Damage criterion and safety assessment approach to tubular joints, Eng Struct, 22 (2000) 424-434.

[64] W.M. Gho, Y. Yang, Parametric Equation for Static Strength of Tubular Circular Hollow Section Joints with Complete Overlap of Braces, Journal of Structural Engineering, 134 (2008) 393-401. 